\title{
Should we ever stop clinical trials for efficacy?
}

\author{
Nicholas A. Fergusson, MSc • Donald E. G. Griesdale, MD, MPH
}

Received: 14 June 2018/Revised: 26 June 2018/Accepted: 9 July 2018/Published online: 13 August 2018

(c) Canadian Anesthesiologists' Society 2018

\section{To the Editor,}

We read with interest the recent trial by Gamble $e t$ al. published in the Journal. ${ }^{1}$ This trial compared the impact of ketamine versus propofol-based anesthesia on response to electroconvulsive therapy in patients with treatmentresistant major depressive disorder. At the request of the research ethics board, the trial was stopped early after randomization of only 24 patients. The justification provided by the board was that "clinical equipoise no longer held." This unfortunate decision greatly limits the interpretability of the results.

Trials can be stopped early for four reasons: harm, futility, new external information that convincingly answers the question or raises issues of harm, and for apparent efficacy. ${ }^{2}$ Stopping a trial solely for apparent efficacy is problematic for several reasons. In the early phases of a clinical trial, especially when sample sizes are small and event rates are low, there can be marked fluctuations in the observed point estimates of treatment efficacy. The STOPIT-2 meta-analysis showed that results were almost always overestimated in trials that were

This letter is accompanied by a reply. Please see Can J Anesth 2018; 65: this issue.

\section{N. A. Fergusson, MSc}

MD Undergraduate Program, Faculty of Medicine, University of British Columbia, Vancouver, BC, Canada

D. E. G. Griesdale, MD, MPH ( $₫)$

Department of Anesthesiology, Pharmacology and Therapeutics, University of British Columbia, Vancouver, BC, Canada

e-mail: donald.griesdale@ubc.ca

D. E. G. Griesdale, MD, MPH

Centre for Clinical Epidemiology and Evaluation, Vancouver

Coastal Health Research Institute, Vancouver, BC, Canada stopped early compared with completed trials posing the same question. ${ }^{3}$ Had these truncated trials been completed, they would likely have shown a "regression to the truth." Although various statistical stopping rules exist, which control for problems of multiplicity, invoking them does not reduce the overestimation of treatment efficacy. ${ }^{2}$

Is it ever reasonable to stop a trial for efficacy? Perhaps only when it is obvious that clinical equipoise no longer exists and continuing a trial would withhold clearly beneficial treatment. This could occur if new and robust data are published during the conduct of the trial. Nevertheless, as highlighted by a recent editorial summarizing the conflicting results of two meta-analyses examining the efficacy of ketamine for electroconvulsive therapy, clinical equipoise clearly exists. ${ }^{5}$ Therefore, in our view, a modestly significant result observed after 24 patients in the trial by Gamble et al. was insufficient grounds for their research ethics board to declare that clinical equipoise was no longer valid. In fact, stopping the trial early for efficacy will likely lead to additional trials trying to answer the same question. ${ }^{2}$ The end result will be more uncertainty, additional use of resources, and delays in disseminating potentially beneficial results-the very consequence we are trying to avoid.

Conflicts of interest Donald Griesdale is a member of the editorial board for the Journal. Donald Griesdale is supported by a Health Professional-Investigator Award from the Michael Smith Foundation for Health Research.

Editorial responsibility This submission was handled by Dr. Gregory L. Bryson, Deputy Editor-in-Chief, Canadian Journal of Anesthesia. 


\section{References}

1. Gamble JJ, Bi H, Bowen R, et al. Ketamine-based anesthesia improves electroconvulsive therapy outcomes: a randomizedcontrolled study. Can J Anesth 2018; 65: 636-46.

2. Bassler D, Montori VM, Briel M, Glasziou P, Guyatt G. Early stopping of randomized clinical trials for overt efficacy is problematic. J Clin Epidemiol 2008; 61: 241-6.
3. Bassler D, Briel M, Montori VM, et al. Stopping randomized trials early for benefit and estimation of treatment effects: systematic review and meta-regression analysis. JAMA 2010; 303: 1180-7.

4. Pocock SJ. Current controversies in data monitoring for clinical trials. Clin Trials 2006; 3: 513-21.

5. Andrade $C$. Ketamine as anaesthesia for ECT: is there room to improve a gold standard treatment? Br J Psychiatry 2018; 212: 129-30. 